\title{
Risk Factors for Recurrence of Disc Herniation After Single- Level Lumbar Discectomy
}

\author{
Yong Guk Kim, Joo Chul Yang, Tae Wan Kim \\ Department of Neurosurgery, VHS Medical Center, Seoul, Korea
}

Objective: Herniated nucleus pulposus is a common disease of the lumbar spine. Recurrence of disc herniation and subsequent disc degeneration are the most common problems following discectomy. Many first-time lumbar discectomy patients experience favorable outcomes; however, same-level recurrent discectomy can occasionally induce unfavorable results. Therefore, in this study, we retrospectively analyzed the risk factors for recurrence of lumbar disc herniation after discectomy.

Methods: From January 2013 to December 2015, 226 patients underwent one-level discectomy in our department. We excluded patients with less than two years of follow-up, a previous spine deformity with a compression fracture, foraminal or extraforaminal discs, or a history of previous lumbar operation history, leaving 71 selected patients. Patients were divided into recurrent and non-recurrent groups and various factors were retrospectively compared between the groups.

Results: Patients with preoperative disc space narrowing experienced recurrence less commonly; however, this was not statistically significant $(10.0 \%$ and $25.5 \%$, respectively; $p=0.150)$. A disc height decrease of more than $20 \%$ during the follow-up period was a statistically significant risk factor for recurrence ( $36.4 \%$ and $14.3 \%$, respectively; $p=0.035)$, and grades 3 and 4, compared to grades 1 and 2, facet joint degeneration were also statistically significant risk factors for recurrence of disc herniation ( $41.2 \%$ and $14.8 \%$, respectively; $p=0.020$ ).

Conclusion: Patients who underwent more than a moderate degree of preoperative facet joint degeneration on the operated side and for whom the progression of disc space height decreased during the follow-up period may require closer observation for recurrence of disc herniation.

Key Words: Nucleus pulposus; Discectomy; Zygapophyseal joint; Recurrence

\section{INTRODUCTION}

Herniated nucleus pulposus is a common disease of the lum-

Received: June 1, 2021 Revised: June 16, 2021 Accepted: June 18, 2021 Corresponding Author: Tae Wan Kim

Department of Neurosurgery, VHS Medical Center, 53 Jinhwangdo-ro, 61gil, Gangdong-gu, Seoul 05368, Korea.

Tel: +82-2-2225-1363, Fax: +82-2-2225-4152,

E-mail: euro3399@naver.com

ORCID: https://orcid.org/0000-0001-7650-3331 bar spine, and discectomy is the standard treatment method for this disease. Recurrence of disc herniation and subsequent disc degeneration are the most common problems after discectomy. While the recurrence rate of disc herniation varies between studies, it is known to be about $5 \%$ to $15 \%$ [1-4], irrespective of the surgical method. A retrospective study showed that nearly $25 \%$ of discectomy patients experience recurrent herniation on follow-up radiographic evaluation; however, most of them are asymptomatic [5]. In $15 \%$ to $25 \%$ of discectomy patients, back pain recurs after two-year follow-up [6]. Recurrence of disc 
herniation after lumbar discectomy may re-aggravate back pain, radiating pain, and reduce the quality of life. Recurrence of disc herniation is the primary cause of the poor outcome of discectomy. A more aggressive removal of disc material can not only reduce the recurrence of disc herniation, but can also cause persistent back pain due to endplate damage and acceleration of disc height decrease [3,7]. The differential diagnosis between recurrence of disc herniation and scar tissue formation at the operative site is also essential. Many first-time lumbar discectomy patients experience favorable outcomes; however, same-level recurrent discectomy occasionally induces unfavorable results. Therefore, we retrospectively analyzed the risk factors for the recurrence of lumbar disc herniation after discectomy.

\section{MATERIALS AND METHODS}

\section{Patient Selection}

This study was approved by the Institutional Review Board of our hospital (BOHUN 2020-08-027). From January 2013 to December 2015, 226 patients underwent one-level discectomy in our department. We excluded patients with a follow-up period of less than two years, previous spine deformity with a compression fracture, foraminal or extraforaminal disc, reoperation within six months due to remaining disc, and previous lumbar operation history including the same and other levels. In total, we selected 71 patients. Recurrence of disc herniation is defined as recurrence on the same-level, or on the ipsilateral or contralateral side, at least six months after the primary operation. When the symptoms were affected by daily activity, we assessed the patient's condition and the level of symptom recurrence. All patients underwent magnetic resonance (MR) imaging before primary discectomy.

\section{Analytic Parameters}

We analyzed patients' demographic parameters such as age/ sex, smoking history, diabetes mellitus (DM), and body mass index (BMI). Radiological parameters included operated disc herniation level, discectomy side (right, left, or both), change of lumbar disc height during the follow-up period, degree of Modic change, disc degeneration, facet joint degeneration, type of disc herniation, and paraspinal muscle atrophy.

The level of disc herniation was divided into the L 4-5 level and other levels. The side of the discectomy was defined as right, left, or both. Lumbar disc height was calculated by adding the anterior, middle, and posterior disc heights and subsequently dividing by three. We divided the patients into two groups based on whether or not the disc height decreased by more than $20 \%$. Disc space narrowing is defined as reducing disc space height compared to adjacent disc space on the lateral view. Using sagittal T1, T2-weighted image (WI) on MR imaging, the Modic change was investigated by type 0 , I, II, and III on the operated level, with type 0 indicating the absence of Modic change. The degree of disc degeneration was classified according to the Pfirrmann classification. It was divided into grades I, II, III, IV, and V. Facet joint degeneration was graded according to Pathria's criteria and divided into grades $1,2,3$, and 4 (Table 1). The type of disc herniation was defined as either protrusion, extrusion, and sequestration. Paraspinal muscle atrophy was classified based on the Goutallier grading system on axial T2-WI on the herniated disc level, and was divided into grades $0,1,2,3$, and 4 .

\section{Statistical Analysis}

Fisher's exact test and t-test were used for statistical analysis using SPSS (version 18.0, SPSS Inc. Chicago, IL, USA). A p-value of less than 0.05 was considered statistically significant.

\section{RESULTS}

The study included 58 men and 13 women. The mean age was $61.89 \pm 13.38$ years (range 21-82 years), and the mean follow-up period was $36.90 \pm 12.20$ months (range $24-70$ months). Among the patients, 15 experienced recurrence (21.1\%). The mean time for recurrence of disc herniation was $17.47 \pm 11.24$ months (range 8-46 months). All patients with recurrence underwent reoperation.

\section{Demographic Parameters}

Of the 71 patients $13 / 58$ male and 2/13 female patients experienced recurrence $(22.4 \%$ and $15.5 \%$, respectively; $\mathrm{p}=0.575)$. In patients aged $>65$ years, ten patients had recurrence among the 46 , and of those aged $<65$ years, five among the $25(21.7 \%$ and $20.0 \%$, respectively; $p=0.864$ ). Smokers experienced recurrence more commonly than nonsmokers; however, the difference was not statistically significant $(29.2 \%$ and $17.0 \%$, respectively; $\mathrm{p}=0.236$ ). Patients treated for DM experienced recurrence more commonly; however, the difference was not statisti-

Table 1. Pathria's criteria for facet joint degeneration

\begin{tabular}{ll}
\hline Grade 1 & Normal: no degenerative finding \\
2 & Mild: joint space narrowing or mild osteophyte \\
3 & Moderate: sclerosis or moderate osteophyte \\
4 & Severe: marked osteophyte or subchondral cyst
\end{tabular}


cally significant $(25.0 \%$ and $19.6 \%$, respectively; $\mathrm{p}=0.617)$. Non-overweight patients ( $<25$ on the BMI scale) experienced recurrence less commonly than overweight patients $(12.0 \%$ and $26.1 \%$, respectively; $\mathrm{p}=0.165$ ) (Table 2 ).

\section{Radiological Parameters}

Of the patients who underwent an operation on L 4-5, 11/45 experienced recurrence, while 4 patients experienced recurrence at other levels (24.4\% and $15.4 \%$, respectively; $\mathrm{p}=0.368$ ). The discectomy side was also not related to recurrence rate (right, left, and both: $18.2 \%, 26.7 \%$, and $12.5 \%$, respectively; $\mathrm{p}=0.582$ ). A decrease in disc height by more than $20 \%$ during the follow-up period was considered a risk factor for recurrence (36.4\% and $14.3 \%$, respectively; $\mathrm{p}=0.035$ ); the mean preoperative disc height was decreased from $11.71 \pm 1.69 \mathrm{~mm}$ to $9.67 \pm 1.86 \mathrm{~mm}$ in the recurrence group and $11.16 \pm 2.44 \mathrm{~mm}$ to $9.89 \pm 2.24 \mathrm{~mm}$ in the non-recurrence group.

Patients who experienced preoperative disc space narrowing observed recurrence less commonly than those who did not; however, this was not statistically significant $(10.0 \%$ and $25.5 \%$, respectively; $\mathrm{p}=0.150$ ). The recurrence rate in the absence of preoperative Modic change patients was similar to that in the presence of preoperative Modic change patients (20.4\% and $22.3 \%$, respectively; $\mathrm{p}=1.000$ ).

Patients with preoperative disc degeneration grades III and IV experienced recurrence more commonly than those who grade I and II (22.5\% and $17.7 \%$, respectively; $\mathrm{p}=0.747)$. Extrusion-type disc herniation recurred more commonly than protrusion and sequestration type (30.8\%, 20.5\%, and $15.8 \%$, respectively; $\mathrm{p}=0.589$ ).

Grades 3 and 4 facet joint degeneration were a risk factor for disc herniation compared to grades 1 and 2 (41.2\% and $14.8 \%$, respectively; $\mathrm{p}=0.020$ ). The degree of paraspinal muscle atrophy was not observed to be a risk factor (grade 1 and 2: grade 3 and $4,21.4 \%$ and $20.0 \%$, respectively; $\mathrm{p}=0.904)$ (Table 3 ).

\section{DISCUSSION}

Studies have revealed that various factors can predispose individuals to disc herniation. Disc reherniation is a common cause of symptom recurrence after discectomy. In most cases, when disc reherniation occurs, the symptoms observed before primary discectomy reappear. Differential diagnosis between disc reherniation and postoperative epidural scar formation is also essential, and enhanced MR imaging is helpful for this pulpose [8].

Old age may be a risk factor for increased recurrence of disc herniation [9]. However, other reports have demonstrated that the younger generation with a high disability is at a high risk of recurrence, and a history of previous trauma before recurrence is common $[10,11]$. One study showed that female patients are more likely to experience recurrence [12]; however, another study contradicted this assertion [11]. Smoking influences cell proliferation, extracellular matrix production, and viability of nucleus pulposus by nicotine effect [13]. It induces disc degeneration and protects annular healing after discectomy, and may also be an important factor in disc reherniation [14].

High BMI, postoperative Oswestry disability index and a high degree of disc degeneration are also risk factors for recurrence of disc herniation $[2,9,15,16]$. Obesity and type 2 diabetes are important factors for disc degeneration [17]. Thus, favorable outcomes after discectomy are not common in diabetic patients [17]. Obesity is influenced by mechanical overloading of the spinal segment, and hyperglycemia directly affects disc cell viability. Intervertebral disc nutrition may be controlled in diabetic patients due to difficulties in diffusing of nutrients and oxygen delivery through the cartilaginous end-plate [18]. In our study, age, sex, smoking and DM history, and BMI were

Table 2. Patients' factors that influence disc recurrence

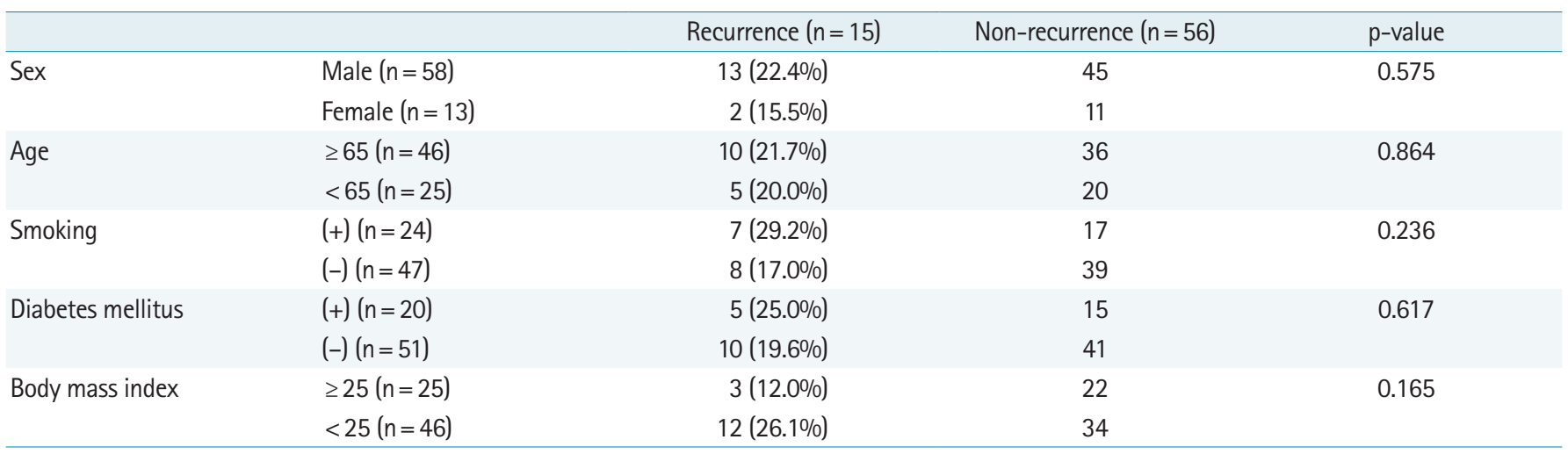


Table 3. Radiological factors that influence disc recurrence

\begin{tabular}{|c|c|c|c|c|}
\hline & & Recurrence $(n=15)$ & Non-recurrence $(n=56)$ & $\mathrm{p}$-value \\
\hline \multirow[t]{2}{*}{ Level } & $L 4-5(n=45)$ & $11(24.4 \%)$ & 34 & 0.368 \\
\hline & other level $(n=26)$ & $4(15.4 \%)$ & 22 & \\
\hline \multirow[t]{3}{*}{ Discectomy side } & Right $(n=33)$ & $6(18.2 \%)$ & 27 & 0.582 \\
\hline & Left $(n=30)$ & $8(26.7 \%)$ & 22 & \\
\hline & Both $(n=8)$ & $1(12.5 \%)$ & 7 & \\
\hline \multirow[t]{2}{*}{ Disc height decrease during follow-up } & $\geq 20 \%(n=22)$ & $8(36.4 \%)$ & 14 & $0.035^{*}$ \\
\hline & $<20 \%(n=49)$ & $7(14.3 \%)$ & 42 & \\
\hline \multirow[t]{2}{*}{ Preoperative disc space narrowing } & $(+)(n=20)$ & $2(10.0 \%)$ & 18 & 0.150 \\
\hline & $(-)(n=51)$ & $13(25.5 \%)$ & 38 & \\
\hline \multirow[t]{4}{*}{ Modic change } & $0(n=49)$ & $10(20.4 \%)$ & 39 & 0.943 \\
\hline & $I(n=6)$ & $1(16.7 \%)$ & 5 & \\
\hline & II $(n=13)$ & $3(23.1 \%)$ & 10 & \\
\hline & III $(n=3)$ & $1(33.3 \%)$ & 2 & \\
\hline \multirow[t]{2}{*}{ Disc degeneration (Pfirrman grade) } & I and II $(n=31)$ & $6(17.7 \%)$ & 25 & 0.747 \\
\hline & III and IV $(n=40)$ & $9(22.5 \%)$ & 31 & \\
\hline \multirow[t]{3}{*}{ Type of disc herniation } & Protrusion $(n=39)$ & $8(20.5 \%)$ & 31 & 0.589 \\
\hline & Extrusion $(n=13)$ & $4(30.8 \%)$ & 9 & \\
\hline & Sequestration $(n=19)$ & $3(15.8 \%)$ & 16 & \\
\hline \multirow[t]{2}{*}{ Facet joint degeneration (Pathria's criteria) } & 1 and $2(n=54)$ & $8(14.8 \%)$ & 46 & $0.020^{*}$ \\
\hline & 3 and $4(n=17)$ & $7(41.2 \%)$ & 10 & \\
\hline \multirow[t]{2}{*}{ Paraspinal muscle atrophy (Goutallier grade) } & 1 and $2(n=56)$ & $12(21.4 \%)$ & 44 & 0.904 \\
\hline & 3 and $4(n=15)$ & 3 (20.0\%) & 12 & \\
\hline
\end{tabular}

${ }^{*} \mathrm{p}<0.05$ Fisher's exact test.

not independent factors for disc herniation recurrence.

The highest rate of reherniation occurred when large and massive annular defects were observed. Cases of extruded disc herniation with large annular defects had the most increased recurrence risk [8]. Other studies have shown that disc reherniation occurs more commonly in protrusion-type herniation [12] and subligamentous disc herniation [19]. In our study, extrusiontype disc herniation was more common than the protrusion type; however, this was not statistically significant. The degree of disc degeneration was related to the recovery rate of annulus fibrosus after discectomy [4]. Annular repair or leave may help reduce reherniation of disc, without increasing perioperative risk [7]; however, none of the patients in this study underwent annular repair. The results of a study revealed that disc reherniation is commonly noted at the L 4-5 level; however, it was not statistically significant [12]. Our study showed similar results.

Standard discectomy is more helpful in reducing reherniation of the disc compared to herniectomy, to a non-statistically significant degree [20]. Subtotal or aggressive discectomy (more resection of disc material after extruded or protruded disc removal) has a lower recurrent disc herniation rate than a limited discectomy. The overall outcome was still less satisfactory [3,21]. Persistent back or leg pain after discectomy is more common than limited discectomy [22]. However, the shortterm follow-up results of less than two years did not differ between the two operative methods [21]. All patients in this study underwent subtotal discectomy.

Degenerative spine segments with preserved disc height are more prone to spinal instability than a collapsed disc [23]. A higher preoperative disc height is also a predisposing factor for recurrence [16]. After discectomy, the progression of disc degeneration may cause persistent back pain, especially in young patients, whereas maintaining disc height may increase the recurrence rate [24]. When the disc height decreases by more than $50 \%$, the spine segment's stability is improved [14]. In contrast, the progression of disc height decrease by more than $20 \%$ during follow-up was a statistically significant factor influencing recurrence of disc herniation in our study.

The occurrence of disc space narrowing after discectomy is common; however, the correlation with prognosis is not significant. Disc height index (DHI) and sagittal range of motion (sROM) are independent factors related to disc reherniation. More than $10^{\circ}$ of sROM and high DHI induce reherniation 
[14]. Larger sROM and associated lumbosacral transitional vertebrae are independent risk factors for recurrent disc herniation [25].

Disc recurrence was more common on L 4-5 than on other levels $[2,11]$. Modic changes are strongly correlated with back pain, especially Modic I change [26], disc degeneration and severity of back pain [27]. Greater Modic endplate changes are risk factors for recurrence [16]. In our study, Modic change was not influenced by recurrence, while severe disc degeneration was influenced by recurrence; however, this was not statistically significant.

The relationship between facet joint degeneration and disc recurrence has yet to be discussed. Most facet joint degeneration appeared at the disc space level with advanced disc degenration [28]. Most cases of disc degeneration are preceded by facet joint degeneration. The appearance of facet joint degeneration induces increased disc loading, which may cause progression of disc degeneration [29]. Severe disc degeneration is also a predisposing factor for reherniation $[2,4]$. This mechanism of facet joint degeneration may influence disc recurrence.

Facet joint orientation and tropism may be important factors in inducing recurrent disc herniation. The incidence of recurrent lumbar disc herniation increases when facet orientation is decreased and facet tropism is decreased [30]. But, facet tropism did not correlate with facet joint degeneration [31]. Facet joint degeneration was a predisposing factor for recurrent disc herniation in our study.

Our study's limitation is its retrospective design, variable follow-up periods, and that the volume of the removed disc was different in each case.

\section{CONCLUSION}

A disc space height decrease of more than $20 \%$ during the follow-up period, along with preoperative disc space height and facet joint degeneration grade 3 and 4 on Pathria's classification were risk factors for disc reherniation. Patients who experienced preoperative facet joint degeneration at the operation site and progressive disc space height decrease during the follow-up period may require closer observation for disc reherniation.

\section{CONFLICTS OF INTEREST}

No potential conflict of interest relevant to this article was reported.

\section{REFERENCES}

1. Ambrossi GL, McGirt MJ, Sciubba DM, Witham TF, Wolinsky JP, Gokaslan ZL, et al. Recurrent lumbar disc herniation after single-level lumbar discectomy: incidence and health care cost analysis. Neurosurgery 2009;65:574-578; discussion 578

2. Beack JY, Chun HJ, Bak KH, Choi KS, Bae IS, Kim KD. Risk factors of secondary lumbar discectomy of a herniated lumbar disc after lumbar discectomy. J Korean Neurosurg Soc 2019;62:586-593

3. Carragee EJ, Spinnickie AO, Alamin TF, Paragioudakis S. A prospective controlled study of limited versus subtotal posterior discectomy: short-term outcomes in patients with herniated lumbar intervertebral discs and large posterior anular defect. Spine (Phila Pa 1976) 2006;31:653-657

4. Cinotti G, Roysam GS, Eisenstein SM, Postacchini F. Ipsilateral recurrent lumbar disc herniation. A prospective, controlled study. J Bone Joint Surg Br 1998;80:825-832

5. Lebow RL, Adogwa O, Parker SL, Sharma A, Cheng J, McGirt MJ. Asymptomatic same-site recurrent disc herniation after lumbar discectomy: results of a prospective longitudinal study with 2-year serial imaging. Spine (Phila Pa 1976) 2011;36:2147-2151

6. Parker SL, Mendenhall SK, Godil SS, Sivasubramanian P, Cahill K, Ziewacz J, et al. Incidence of low back pain after lumbar discectomy for herniated disc and its effect on patient-reported outcomes. Clin Orthop Relat Res 2015;473: 1988-1999

7. Bailey A, Araghi A, Blumenthal S, Huffmon GV; Anular Repair Clinical Study Group. Prospective, multicenter, randomized, controlled study of anular repair in lumbar discectomy: two-year follow-up. Spine (Phila Pa 1976) 2013; 38:1161-1169

8. Lee JK, Amorosa L, Cho SK, Weidenbaum M, Kim Y. Recurrent lumbar disk herniation. J Am Acad Orthop Surg 2010;18:327-337

9. Dobran M, Nasi D, Paracino R, Gladi M, Costanza MD, Marini A, et al. Analysis of risk factors and postoperative predictors for recurrent lumbar disc herniation. Surg Neurol Int 2019;10:36

10. Hlubek RJ, Mundis GM Jr. Treatment for recurrent lumbar disc herniation. Curr Rev Musculoskelet Med 2017;10:517520

11. Suk KS, Lee HM, Moon SH, Kim NH. Recurrent lumbar disc herniation: results of operative management. Spine (Phila Pa 1976) 2001;26:672-676 
12. Oh JT, Park KS, Jung SS, Chung SY, Kim SM, Park MS, et al. Surgical results and risk factors for recurrence of lumbar disc herniation. Korean J Spine 2012;9:170-175

13. Akmal M, Kesani A, Anand B, Singh A, Wiseman M, Goodship A. Effect of nicotine on spinal disc cells: a cellular mechanism for disc degeneration. Spine (Phila Pa 1976) 2004;29:568-575

14. Kim KT, Park SW, Kim YB. Disc height and segmental motion as risk factors for recurrent lumbar disc herniation. Spine (Phila Pa 1976) 2009;34:2674-2678

15. Fotakopoulos G, Makris D, Kotlia P, Tzerefos C, Fountas K. Recurrence is associated with body mass index in patients undergoing a single-level lumbar disc herniation surgery. J Clin Med Res 2018;10:486-492

16. Yaman ME, Kazancı A, Yaman ND, Baş F, Ayberk G. Factors that influence recurrent lumbar disc herniation. Hong Kong Med J 2017;23:258-263

17. Swartz KR, Trost GR. Recurrent lumbar disc herniation. Neurosurg Focus 2003;15:E10

18. Cannata F, Vadalà G, Ambrosio L, Fallucca S, Napoli N, Papalia $\mathrm{R}$, et al. Intervertebral disc degeneration: a focus on obesity and type 2 diabetes. Diabetes Metab Res Rev 2020; 36:e3224

19. Yurac R, Zamorano JJ, Lira F, Valiente D, Ballesteros V, Urzúa A. Risk factors for the need of surgical treatment of a first recurrent lumbar disc herniation. Eur Spine J 2016;25: 1403-1408

20. Landi A, Grasso G, Mancarella C, Dugoni DE, Gregori F, Iacopino $\mathrm{G}$, et al. Recurrent lumbar disc herniation: is there a correlation with the surgical technique? A multivariate analysis. J Craniovertebr Junction Spine 2018;9:260-266

21. McGirt MJ, Ambrossi GL, Datoo G, Sciubba DM, Witham TF, Wolinsky JP, et al. Recurrent disc herniation and longterm back pain after primary lumbar discectomy: review of outcomes reported for limited versus aggressive disc removal. Neurosurgery 2009;64:338-344. discussion 344-345

22. Watters WC 3rd, McGirt MJ. An evidence-based review of the literature on the consequences of conservative versus aggressive discectomy for the treatment of primary disc herniation with radiculopathy. Spine J 2009;9:240-257

23. Hasegawa K, Kitahara K, Hara T, Takano K, Shimoda H, Homma T. Evaluation of lumbar segmental instability in degenerative diseases by using a new intraoperative measurement system. J Neurosurg Spine 2008;8:255-262

24. Yorimitsu E, Chiba K, Toyama Y, Hirabayashi K. Long-term outcomes of standard discectomy for lumbar disc herniation: a follow-up study of more than 10 years. Spine (Phila Pa 1976) 2001;26:652-657

25. Shin EH, Cho KJ, Kim YT, Park MH. Risk factors for recurrent lumbar disc herniation after discectomy. Int Orthop 2019;43:963-967

26. Brinjikji W, Diehn FE, Jarvik JG, Carr CM, Kallmes DF, Murad $\mathrm{MH}$, et al. MRI findings of disc degeneration are more prevalent in adults with low back pain than in asymptomatic controls: a systematic review and meta-analysis. AJNR Am J Neuroradiol 2015;36:2394-2399

27. Mok FP, Samartzis D, Karppinen J, Fong DY, Luk KD, Cheung KM. Modic changes of the lumbar spine: prevalence, risk factors, and association with disc degeneration and low back pain in a large-scale population-based cohort. Spine J 2016;16:32-41

28. Fujiwara A, Tamai K, Yamato M, An HS, Yoshida H, Saotome $\mathrm{K}$, et al. The relationship between facet joint osteoarthritis and disc degeneration of the lumbar spine: an MRI study. Eur Spine J 1999;8:396-401

29. Bashkuev M, Reitmaier S, Schmidt H. Relationship between intervertebral disc and facet joint degeneration: a probabilistic finite element model study. J Biomech 2020;102: 109518

30. Li Z, Gui G, Zhang Y, Zhou Y, Yang M, Chang Y, et al. Are facet joint parameters risk factors for recurrent lumbar disc herniation? A pilot study in a Chinese population. J Clin Neurosci 2020;77:36-40

31. Cui JH, Kim YC, Lee K, Park GT, Kim KT, Kim SM. Relationship between facet joint tropism and degeneration of facet joints and intervertebral discs based on a histological study. J Orthop 2018;16:123-127 